Review Article

\title{
Developing Information Literacy for Students in the Context of Higher Education in Vietnam
}

\author{
Nghiem Xuan Huy ${ }^{1, *}$, Bui Thi Thanh Huyen ${ }^{2}$ \\ ${ }^{I}$ VNU Institute for Education Quality Assurance, 144 Xuan Thuy, Cau Giay, Hanoi, Vietnam \\ ${ }^{2}$ VNU University of Social Sciences and Humanities, 336 Nguyen Trai, Thanh Xuan, Hanoi, Vietnam
}

Received 06 March 2021

Revised 14 April 2021; Accepted 14 April 2021

\begin{abstract}
The context of $4^{\text {th }}$ Industrial Revolution has not only made changes in education methods, but also challenged learners. In higher education, learners are increasingly expected to learn actively by effectively exploring and using different information resources. Therefore, it is universities' mission to acquire students with abilities in identifying their information needs, retrieving needed information, evaluating information, and using information legally and ethically in accordance with adademic regulations. In other words, those abilities are core elements of information literacy, which has been considered as an essential tool for improving students' self-learning and lifelong learning capability at universities in Western countries. This paper aims at analyzing and clarifying the concept of information literacy in the context of Vietnamese higher education, evaluating the role of information literacy in student's learning, and proposing solutions for developing information literacy for student at higher education institutions in Vietnam.
\end{abstract}

Keywords: Information literacy; higher education, learning ability, higher education student, education policies, learning outcomes.

\footnotetext{
${ }^{*}$ Corresponding author.

E-mail address: huynx@vnu.edu.vn

https://doi.org/10.25073/2588-1159/vnuer.4508
} 


\title{
Phát triển năng lực thông tin cho sinh viên trong bối cảnh giáo dục đại học tại Việt Nam
}

\author{
Nghiêm Xuân Huy ${ }^{1, *}$, Bùi Thị Thanh Huyền ${ }^{2}$ \\ ${ }^{1}$ Viện Đảm bảo chất lượng giáo duc, Đại học Quốc gia Hà Nội, \\ 144 Xuân Thủy, Cầu Giấy, Hà Nội, Việt Nam \\ ${ }^{2}$ Truoòng Đại Khoa học Xã hội và Nhân văn, Đại học Quốc gia Hà Nội, \\ 336 Nguyễ̂n Trãi, Thanh Xuân, Hà Nội, Việt Nam \\ Nhận ngày 06 tháng 3 năm 2021 \\ Chỉnh sửa ngày 14 tháng 4 năm 2021; Chấp nhận đăng ngày 14 tháng 4 năm 2021
}

\begin{abstract}
Tóm tắt: Bối cảnh Cách mạng công nghiệp 4.0 không chỉ đang làm thay đổi phương thức đào tạo mà còn đặt ra nhiều thử thách với chính người học. Trong bối cảnh giáo dục đại học, người học ngày càng được yêu cầu học tập một cách chủ động và tích cực trên cơ sở sự tương tác, tiếp cận hiệu quả với các nguồn thông tin, học liệu khác nhau. Do đó, việc trang bị, rèn luyện cho người học khả năng nhận diện nhu cầu thông tin, tìm kiếm thông tin, đánh giá thông tin, sử dụng thông tin một cách đúng pháp luật, hợp đạo đức và các chuẩn mực khoa học là nhiệm vụ quan trọng của trường đại học. Những yếu tố trên chính là các cấu phần cơ bản của "năng lực thông tin", một yếu tố đã và đang được các trường đại học phương Tây xem là nhân tố quan trọng cho việc rèn luyện khả năng tự học, năng lực học tập suốt đời của người học. Bài viết này có mục đích làm rõ và nhất quán khái niệm "năng lực thông tin" đang được sử dụng tại Việt Nam, đánh giá vai trò của năng lực thông tin đối với người học và trường đại học, qua đó đề xuất các giải pháp thúc đẩy phát triển năng lực thông tin cho sinh viên tại các cơ sở giáo dục đại học tại Việt Nam.
\end{abstract}

Tù khóa: Năng lực thông tin, giáo dục đại học, năng lực học tập, sinh viên đại học, chính sách đào tạo, chuẩn đầu ra.

\section{1. Đặt vấn đề}

Năng lực thông tin (từ gốc tiếng Anh là information literacy) thể hiện sự hiểu biết, kỹ năng và tâm thế làm chủ thế giới thông tin của mỗi cá nhân, giúp các cá nhân thích ứng nhanh với các bối cảnh sống, làm việc và học tập [1]. Phát triển năng lực thông tin cho người học, nhất là trong bối cảnh giáo dục đại học, trở thành nhiệm vụ quan trọng đối với nhà trường, nhằm hướng đến hình thành và phát triển khả năng học tập suốt đời của người học. Cơ sở lý thuyết và thực tiễn cho việc phát triển năng lực thông tin cho người học đã được đề cập nhiều trong các nghiên cứu và bối cảnh giáo dục ở các

\footnotetext{
* Tác giả liên hệ.

Địa chỉ email: huynx@vnu.edu.vn

https://doi.org/10.25073/2588-1159/vnuer.4508
}

nước phương Tây [2]. Trong khi đó, ở Việt Nam, khái niệm năng lực thông tin mới chỉ được bắt đầu nghiên cứu, tìm hiểu từ năm 2006 , trong một Hội thảo quốc tế về chủ đề này do Trường Đại học Khoa học Xã hội và Nhân văn, Đại học Quốc gia Hà Nội phối hợp với Liên hiệp các cơ quan thông tin - thư viện thế giới (IFLA) tổ chức. Có thể nói, những công trình nghiên cứu, khung lý thuyết, thực hành trong phát triển năng lực thông tin của các tổ chức, cá nhân chủ yếu được thực hiện và áp dụng trong bối cảnh giáo dục phương Tây. Ở những môi trường như vậy, các cá nhân có tâm thế học tập chủ động, được trang bị kỹ năng công nghệ thông tin từ sớm, được cung cấp tài nguyên thông tin dồi dào. Đó cũng là những điểm khác biệt với bối cảnh giáo dục ở phương Đông nói chung và Việt Nam nói riêng, nơi phong cách học tập "thụ động" (passive learning) khá phổ 
biến ở các lớp học, nơi bị hạn chế khả năng tiếp cận các tài nguyên thông tin do tiếng Anh không phải là ngôn ngữ thứ nhất, nơi trình độ công nghệ thông tin của người học còn hạn chế do điều kiện kinh tế, xã hội còn có những khó khăn. Những điều trên khiến cho việc triển khai các chương trình phát triển năng lực thông tin cho người học có những điểm khác biệt khi thực hiện ở những bối cảnh giáo dục khác nhau. Nói cách khác, không có hình mẫu chung để áp dụng hiệu quả cho việc phát triển năng lực thông tin ở mọi bối cảnh giáo dục và xã hội khác nhau [3]. Do đó, nghiên cứu này được thực hiện nhằm góp phần giải đáp các câu hỏi nghiên cứu sau: trong bối cảnh giáo dục đại học tại Việt Nam, khái niệm năng lực thông tin cần được thể hiện ở những khía cạnh nào? Việc triển khai phát triển năng lực thông tin cho người học ở các trường đại học của Việt Nam có những đặc thù gì và có những giải pháp nào để đảm bảo hiệu quả cho việc phát triển năng lực thông tin cho người học? Nghiên cứu được thực hiện trên cơ sở phân tích, đánh giá một số khái niệm, khung lý thuyết, thực hành tiêu biểu về phát triển năng lực thông tin trong tham chiếu với các đặc thù về bối cảnh giáo dục đại học tại Việt Nam. Từ đó, nghiên cứu đề xuất các định hướng và giải pháp để triển khai phát triển năng lực thông tin cho sinh viên phù hợp với bối cảnh giáo dục đại học tại Việt Nam.

\section{Tổng quan về khái niệm và vai trò của năng lực thông tin trong giáo dục đại học}

\subsection{Khái niệm năng lục thông tin}

Theo các tác giả Spitzer, Eisenberg, và Lowe [4], năng lực thông tin (tạm dịch từ tiếng Anh là "information literacy") được Paul Zurkowski, Chủ tịch Hội công nghiệp Thông tin (Mỹ), đề cập lần đầu tiên vào năm 1974. Đây là thời điểm có sự phát triển bùng nổ của thông tin cũng như nhu cầu sử dụng tài nguyên thông tin. Theo tác giả này, năng lực thông tin là "những kỹ thuật và kỹ năng sử dụng các công cụ thông tin khác nhau cũng như những nguồn lực cơ bản trong việc thiết lập các giải pháp thông tin cho vấn đề của người dùng" $[4$, tr. 22]. Từ năm 1989, sau khi khi Hiệp Hội thư viện Hoa
Kỳ công bố bản báo cáo cuối cùng về vấn đề bùng nổ thông tin, khái niệm năng lực thông tin đã các cơ sở giáo dục đặc biệt chú ý [5].

Hiệp hội các thư viện Đại học và thư viện nghiên cứu Mỹ $[1,6]$ định nghĩa năng lực thông tin là các hiểu biết kỹ năng cho phép các cá nhân có thể "nhận biết thời điểm cần thông tin và có thể định vị, thẩm định và sử dụng thông tin mình cần một cách hiệu quả". Cheek và các cộng sự [7, tr. 2] trích dẫn ý tưởng của McKie khi cho rằng "năng lực thông tin là khả năng nhận biết nhu cầu thông tin, tìm kiếm, tổ chức, thẩm định và sử dụng thông tin trong việc ra quyết định một cách hiệu quả, cũng như áp dụng những kỹ năng này vào việc tự học suốt đời”.

Tại Việt Nam, khái niệm năng lực thông tin được du nhập từ đầu những năm 2000 và được nghiên cứu, phổ biến rộng rãi từ năm 2006 thông qua Hội thảo quốc tế về Năng lực thông tin, được tổ chức tại Đại học Quốc gia Hà Nội với sự tham gia của Hiệp hội quốc tế các tổ chức thông tin và thư viện (IFLA) và các chuyên gia đến từ New Zealand và Australia [6]. Ở thời điểm đó, khái niệm "information literacy" được tạm dịch là "kiến thức thông tin" và được dùng khá rộng rãi trong nhiều nghiên cứu sau đó.

Tuy nhiên, như phân tích phía trên, năng lực thông tin không chỉ đơn thuần là những kỹ năng trong tìm kiếm và khai thác thông tin. Khái niệm "năng lực thông tin" liên quan đến vấn đề làm chủ thế giới thông tin của mỗi cá nhân, thông qua việc tiếp cận, xử lý thông tin; trao đổi và chia sẻ thông tin; hiểu về các khía cạnh đạo đức, pháp luật của việc khai thác, sử dụng thông tin. Như vậy năng lực thông tin liên quan đến 3 vấn đề cốt lõi: kỹ năng thông tin; thái độ chủ động và tích cực trong tiếp cận thông tin; các hiểu biết về khía cạnh đạo đức, pháp luật trong khai thác và sử dụng thông tin.

Như vậy, năng lực thông tin bao gồm cả những kiến thức về các thể chế xã hội và các quyền do pháp luật quy định trong tiếp cận, truy cập và sử dụng các nguồn thông tin $[8,9]$. Đồng thời, năng lực thông tin còn hàm chứa tinh thần trung thực học thuật, thái độ chủ động và tích cực trong khai thác và sử dụng thông tin. Có thể thấy, xét về tổng thể, năng lực thông tin liên 
quan đến việc xác định nhu cầu thông tin, xây dựng các kỹ thuật tìm tin, lựa chọn và xác minh nguồn tin, thẩm định thông tin, tổng hợp và sử dụng thông tin $[9,10]$.

Theo Hiệp hội Các thư viện chuyên ngành và các trường đại học Hoa Kỳ [12], người có năng lực thông tin là người "đã học được cách thức để học. Họ biết cách học bởi họ nắm được phương thức tổ chức tri thức, tìm kiếm thông tin và sử dụng thông tin, do đó những người khác có thể học tập được từ họ. Họ là những người được đã chuẩn bị cho khả năng học tập suốt đời, bởi lẽ họ luôn tìm được thông tin cần thiết cho bất kỳ nhiệm vụ hoặc quyết định nào một cách chủ động”.
Như vậy, có thể nói, "information literacy”, hay còn gọi "năng lực thông tin", là một phạm trù thuộc về năng lực cá nhân, giúp các cá nhân làm chủ, khai thác và sử dụng các nguồn thông tin mà mình tiếp cận được một cách hiệu quả $[2,13]$.

2.2. Vai trò của năng lục thông tin trong bối cảnh giáo dục đại học

2.2.1. Năng lực thông tin đối với sinh viên đại học

Hiện tại, người học đang được học tập trong một môi trường rộng mở với nguồn thông tin đa dạng, phong phú, phức tạp (xem mô tả như Hình 1 dưới đây):

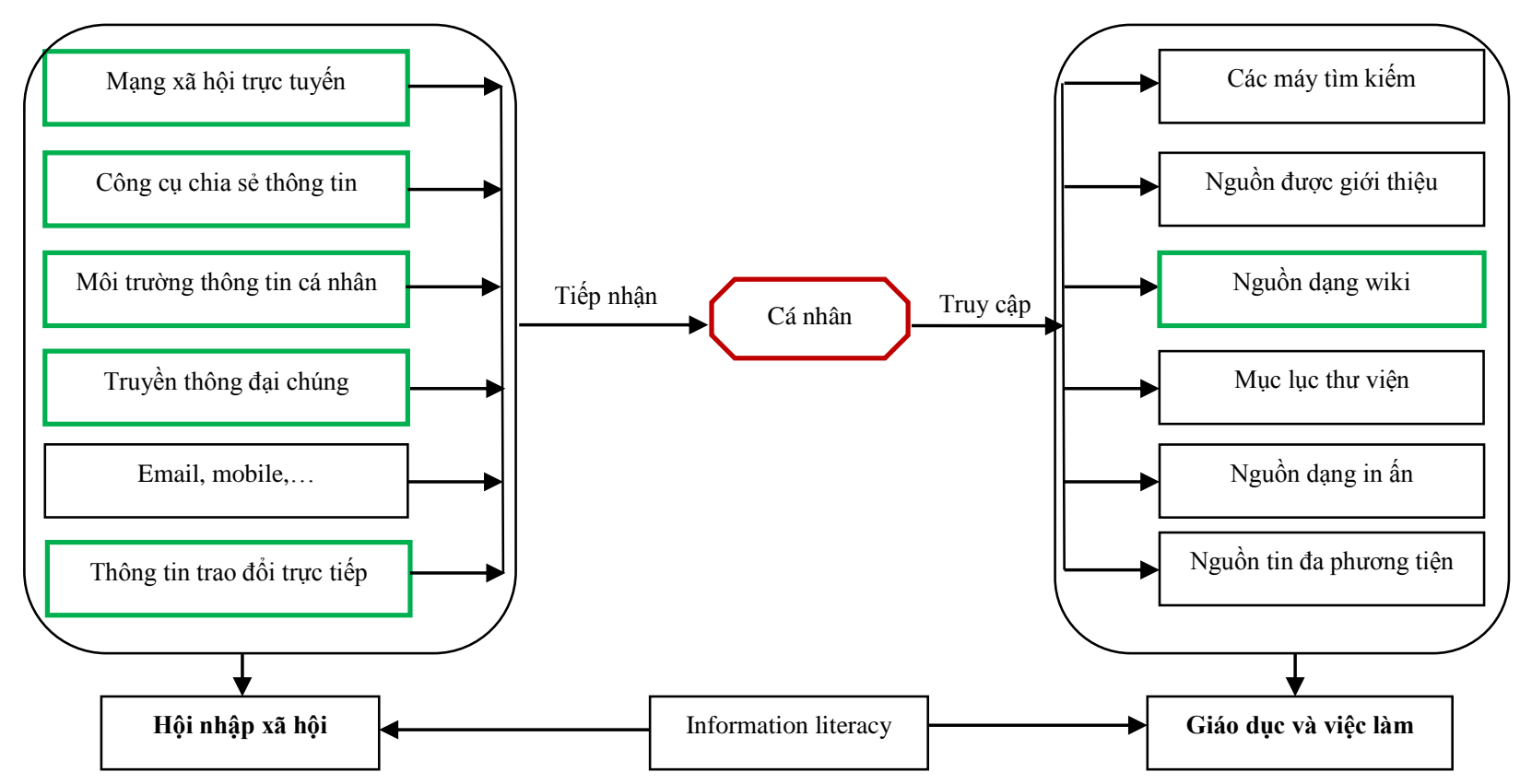

Hình 1. Bối cảnh thông tin của mỗi cá nhân [2, tr. 7].

Như vậy, có thể thấy, người học cùng lúc vừa phải "tiếp nhận" nhiều nguồn thông tin khác nhau, đa phần từ những tương tác xã hội, vừa chủ động "truy cập", tìm kiếm các nguồn thông tin phục vụ nhu cầu học tập và nghề nghiệp. Cho dù ở tâm thế chủ động hay thụ động, người học vẫn phải tiếp nhận thông tin từ các tương tác xã hội và bối cảnh sống (để phục vụ nhu cầu hội nhập xã hội và phát triển cá nhân). Ở chiều ngược lại, để phục vụ nhu cầu học tập và phát triển chuyên môn, người học phải chủ động tìm kiếm, khai thác thông tin một cách hiệu quả và phù hợp thông qua các phương tiện, kênh, công cụ, nguồn khác nhau. Như vậy, bối cảnh thông tin của mỗi cá nhân hiện nay khá phức tạp, đòi hỏi cá nhân phải có năng lực thông tin để tiếp nhận và xử lý thông tin hiệu quả.

Nói một cách khái quát, năng lực thông tin giúp các cá nhân vừa thích nghi, hội nhập xã hội, vừa hỗ trợ nâng cao hiệu quả học tập và phát triển chuyên môn. 
Ở một hệ quy chiếu hẹp hơn là bối cảnh học tập của người học. Trong bối cảnh bùng nổ thông tin và "thế giới phẳng" hiện nay, bối cảnh học tập của người học cũng có nhiều thay đổi, được mở rộng và dựa trên nền tảng nguồn tin đa dạng, phong phú (xem Hình 2).

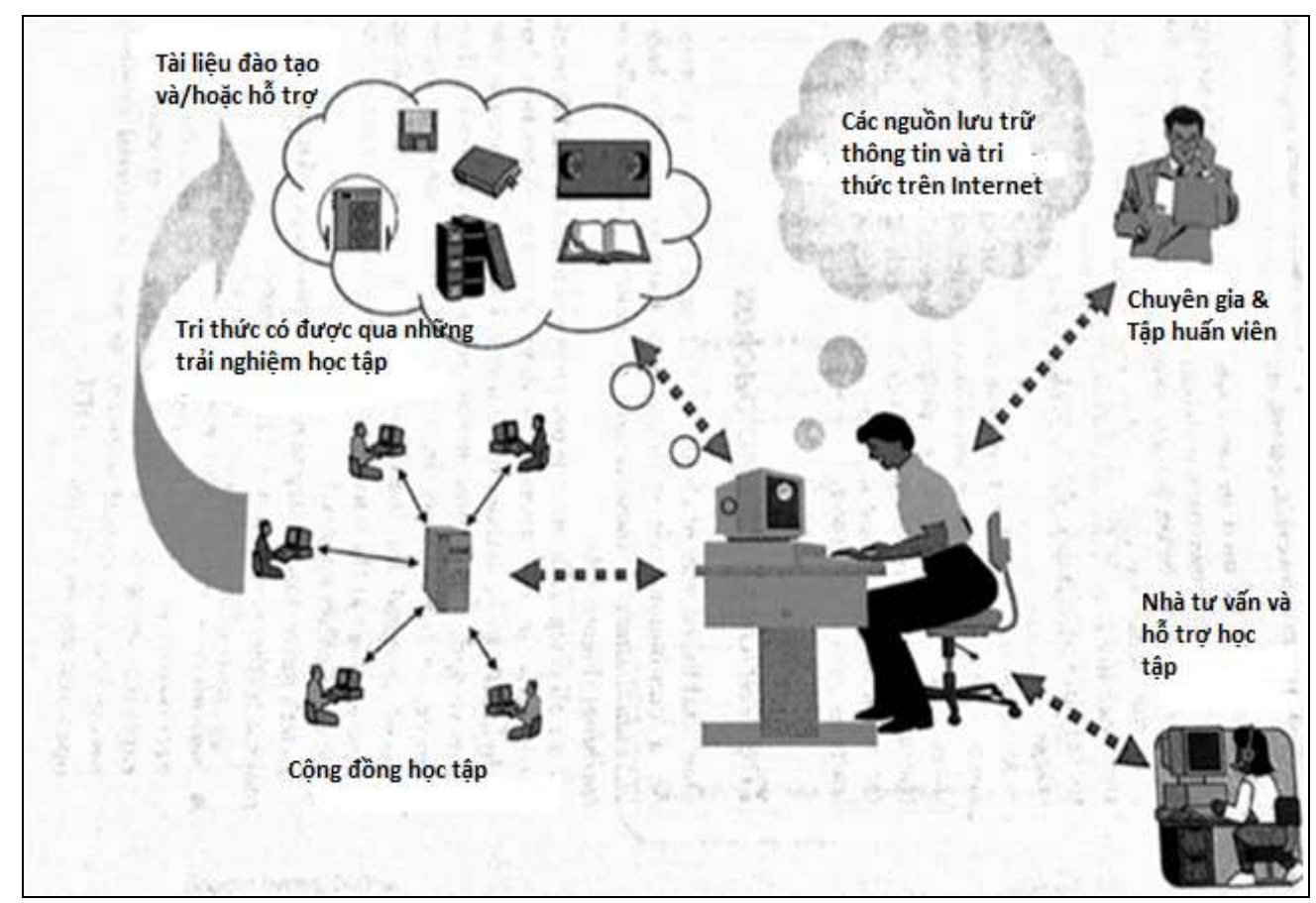

Hình 2. Bối cảnh học tập của mỗi cá nhân [14, tr. 5].

Có thể thấy, giáo viên (nhà tư vấn và hỗ trợ học tập) là một trong rất nhiều nguồn thông tin mà người học tương tác. Những nguồn khác như: học liệu từ thư viện, thông tin trên Internet, thông tin từ cố vấn học tập, thông tin từ các nhóm học tập khác nhau cũng đóng vai trò quan trọng trong việc hình thành nền tảng tri thức cho người học. Để học tốt, người học cũng cần được trang bị năng lực thông tin để tiếp nhận và xử lý những nguồn thông tin này một cách hiệu quả.

Theo những phân tích như vậy, tác giả Rader [15] cho rằng phương pháp giáo dục cần phải được đổi mới nhằm đưa sinh viên trở thành trung tâm của quá trình dạy và học. Eskola (1998), gọi đây là "active teaching" (giảng dạy tích cực), nơi sinh viên không phải là những người tiếp nhận một cách thụ động tri thức, mà phải là người xử lý và tạo ra tri thức một cách chủ động.
Điều này dẫn tới tính cấp thiết của năng lực thông tin trong việc cung cấp cho sinh viên khả năng học tập suốt đời và xem năng lực thông tin là một trong những năng lực cần đạt được sau khi tốt nghiệp đại học (tiêu chí tốt nghiệp). Doskatsch [16, 17] nhấn mạnh đến tính đa dạng, phức tạp trong nhu cầu thông tin của người học, do đó các trường đại học cần phải nắm rõ nhu cầu và hành vi thông tin của sinh viên trước khi triển khai các chương trình phát triển năng lực thông tin cho sinh viên. Bên cạnh đó, Bruce [5] cho rằng khái niệm năng lực thông tin nên phổ biến rộng rãi để sinh viên có thể hiểu một cách rõ ràng và toàn diện.

2.2.2. Chính sách giáo dục trong phát triển năng lực thông tin.

Như chúng ta đã biết, chính sách giáo dục chịu sự tác động sâu sắc từ sự phát triển mạnh mẽ của nền kinh tế tri thức và xã hội thông tin, từ những đòi hỏi mới của thị trường lao động, cũng như sự phát triển nhanh chóng của công 
nghệ. Có thể thấy được điều này thông qua những thay đổi trong mục tiêu giáo dục và các tiêu chí đối với sinh viên tốt nghiệp của các cơ sở giáo dục đại học. Bundy [18, tr. 4] khẳng định rằng "việc dạy và học đang được đổi mới thông qua triết lý lấy sinh viên làm trung tâm, qua việc hướng vào các tiêu chí tốt nghiệp, những tương tác nhằm tận dụng tối đa nguồn thông tin sẵn có và công nghệ thông tin - viễn thông". Trên thực tế, việc cung cấp cho sinh viên khả năng học tập một cách độc lập và hiệu quả trong suốt cả cuộc đời họ đang được xem như là một trong những mục tiêu tối thượng của các thiết chế giáo dục, đặc biệt là các trường đại học. Theo Viện Năng lực thông tin Úc - New Zealand [3], việc phát triển người học có khả năng học tập suốt đời đóng vai trò trung tâm đối với nhiệm vụ đào tạo của của các cơ sở đào tạo, đồng thời vấn đề này đang ngày càng được phản ánh rõ trong các tiêu chí tốt nghiệp đối với sinh viên.

Cùng quan điểm như trên, Bundy $[18$, tr. 5] cho rằng những thách thức đó là động lực và cơ sở để phác họa những tiêu chí tốt nghiệp đối với sinh viên. Để đáp ứng những tiêu chí này, quá trình đào tạo người học ở trường đại học cần được tích hợp với việc phát triển năng lực thông tin. Tại Úc, những phẩm chất liên quan đến năng lực thông tin đã được tích hợp vào các tiêu chí tốt nghiệp đối với sinh viên ở rất nhiều trường đại học [19].

Như vậy, việc phát triển năng lực thông tin cho người học cần phải được phản ánh trong chính sách giáo dục của các trường đại học và được tất cả các thành viên trong cơ sở giáo dục đó hiểu rõ. Điều này cho phép các trường đại học triển khai các chương trình phát triển năng lực thông tin cho sinh viên một cách chủ động và hiệu quả.

Để có thể có một chiến lược đào tạo năng lực thông tin hợp lý và các chương trình năng lực thông tin hiệu quả dành cho sinh viên, các nhà quản lý/phát triển giáo dục, các cán bộ thư viện và các giảng viên phải hợp tác với nhau chặt chẽ [21]. Trong mối quan hệ này, theo Bruce $[5,20,22]$, cán bộ thư viện và giảng viên đóng vai trò là người cung cấp thông tin về thực tế nhu cầu thông tin của sinh viên. Đây là cơ sở đặc biệt quan trọng cho các chính sách giáo dục trong trường đại học.

\section{Những vấn đề đặt ra đối với việc phát triển năng lực thông tin cho sinh viên đại học tại Việt Nam}

Qua những phân tích như trên, có thể thấy hầu hết các công trình nghiên cứu về năng lực thông tin trên thế giới đều có những vấn đề cần lưu ý như sau:

Một là: bối cảnh nghiên cứu là không gian học thuật và môi trường đào tạo ở các nước phương Tây - nơi có sự khác biệt rất rõ về văn hóa học tập, triết lý giáo dục, đặc thù người học, cơ sở hạ tầng, tài nguyên thông tin so với bối cảnh tương ứng ở Việt Nam.

Hai là: Các tác giả chủ yếu là các nhà khoa học hoạt động trong lĩnh vực thông tin - thư viện và nhìn nhận vấn đề phát triển năng lực thông tin dưới góc độ của hoạt động thông tin - thư viện. Cần có một tiếp cận toàn diện với sự tham gia của tất cả các bên liên quan (nhà quản lý, giảng viên, cố vấn học tập,...).

Ba là: Các nghiên cứu mới chủ yếu dừng ở việc phân tích, đánh giá mối quan hệ giữa giảng viên và cán bộ thư viện trong hoạt động phát triển năng lực thông tin cho sinh viên.

Tại Việt Nam, vấn đề phát triển năng lực thông tin trong các bối cảnh thư viện khác nhau đã bă̆t đầu được giới chuyên môn chính thức đề cập đến từ năm 2006. Tuy nhiên, các học giả và những người làm nghề thông tin - thư viện ở Việt Nam mới chủ yếu bàn đến khái niệm và vai trò của năng lực thông tin nói chung. Các khía cạnh ứng dụng của khái niệm này chưa được bàn thảo rộng rãi. Đặc biệt, vấn đề liên quan đến vai trò của giảng viên trong lĩnh vực này hầu như chưa được bàn đến. Nếu xem năng lực thông tin là khả năng "học được cách thức để học" [1], thì việc phát triển năng lực thông tin cho người học nên được xuất phát và thực hành trước hết từ chính giáo viên.

Tuy nhiên, với vai trò là bộ phận lưu trữ, phục vụ, cung cấp thông tin trong trường đại học, những người làm công tác thông tin - thư 
viện cũng đóng vai trò là bộ phận kiến tạo không gian thông tin học thuật và hỗ trợ trực tiếp người học trong quá trình tìm kiếm, khai thác thông tin. Trường đại học cần xây dựng một cơ chế phối hợp giữa giáo viên và cán bộ thư viện trong thiết kế, xây dựng và triển khai các hoạt động phát triển năng lực thông tin cho người học.

Một đặc thù nữa cần đề cập đến trong bối cảnh giáo dục đại học Việt Nam, đó là kỹ năng học tập và hành vi thông tin của sinh viên. Nghiên cứu cho thấy, do chịu ảnh hưởng không nhỏ của truyền thống khoa cử và văn hóa Nho giáo, sinh viên Việt Nam khá thụ động trong phong cách học tập (thụ động trong tương tác với giáo viên, trong việc đưa ra ý tưởng học tập, trong tiếp cận các nguồn lực hỗ trợ học tập). Bên cạnh đó, sinh viên còn khá thụ động trong tiếp cận thông tin phục vụ học tập (thường là tiếp nhận các học liệu do giáo viên giới thiệu là chủ yếu). Đây là điểm cần đặc biệt chú ý khi triển khai các hoạt động phát triển năng lực thông tin cho người học tại Việt Nam.

Qua những phân tích như trên, có thể thấy để phát triển năng lực thông tin cho người học cần những giải pháp đồng bộ, bền vững và phù hợp với đặc thù bối cảnh giáo dục tại Việt Nam. Không chỉ cần quan điểm đúng về khái niệm năng lực thông tin, việc triển khai phát triển năng lực thông tin cho người học còn cần xem xét yếu tố phong cách học tập của người học, vai trò của giảng viên và sự phối hơp giữa giảng viên và những người làm công tác thư viện tại trường đại học.

Về mặt khái niệm, cần hiểu rõ năng lực thông tin không đơn thuần là một kỹ năng hay nhóm kỹ năng, do đó không thể trang bị cho người học chỉ thông qua những khóa học ngắn hạn. Kiến thức, kỹ năng thông tin cần được áp dụng, sử dụng trong suốt quá trình học tập của người học ở trường đại học, từ đó hình thành được năng lực bền vững cho người học.

Bên cạnh đó, do một trong những sứ mệnh quan trọng của trường đại học là tạo lập năng lực học tập suốt đời cho người học, việc phát triển năng lực thông tin cần được xem là một trong những phương thức đặc biệt cần thiết để thực hiện chuẩn đầu ra cho sinh viên theo học các chương trình đào tạo [10]. Việc tích hợp các nội dung, hoạt động liên quan đến phát triển năng lực thông tin vào mỗi chương trình đào tạo là một trong những giải pháp đặc biệt quan trọng, cần ưu tiên.

Ngoài vấn đề về tích hợp như trên, các giải pháp cũng sẽ hướng tới thúc đẩy vai trò của các bên liên quan (giảng viên, cán bộ thư viện, cố vấn học tập,...) trong việc phát triển năng lực thông tin cho người học. Việc phát triển năng lực thông tin cho sinh viên cần được triển khai thông qua quá trình thực hiện các nội dung chương trình đào tạo của giảng viên, việc tổ chức các sản phẩm, dịch vụ thông tin, hỗ trợ thông tin của thư viện dành cho sinh viên.

\section{Giải pháp phát triển năng lực thông tin cho sinh viên trong giáo dục đại học tại Việt Nam}

\subsection{Tích hơp việc phát triển năng lực thông tin trong các hoạt động đào tạo}

Tích hợp các nội dung gắn với phát triển năng lực thông tin cho người học vào chương trình đào tạo có thể được xem như là cốt lõi của bất kỳ chương trình phát triển năng lực thông tin nào ở bậc đại học. Mục tiêu của quá trình này là cung cấp cho sinh viên các kỹ năng và kiến thức về thông tin thông qua nội dung và cấu trúc của bài giảng, các hoạt động dạy và học, các bài kiểm tra đánh giá kết quả học tập, và một nguồn thông tin dồi dào, phù hợp với yêu cầu của họ. Đây là biểu hiện rõ nét của việc đào tạo lấy sinnh viên làm trung tâm và chính sách về học tập suốt đời. Điều đó có nghĩa là, nếu như việc phát triển năng lực thông tin cho sinh viên không được tích hợp vào quá trình đào tạo, các môn học, khóa học thì những tiêu chí tốt nghiệp - vốn dĩ hướng vào mục tiêu học tập suốt đời - mà nhà trường đặt ra không thể thực thi được. Warmkessel và McCade [23], Farmer [24], Brown, Murphy, và Nanny [25], đều cho rằng việc tích hợp đó là không thể thiếu được đối với sự thành công của các chương trình phát triển năng lực thông tin dành cho sinh viên.

Như đã trình bày ở trên, mỗi trường đại học có những chiến lược triển khai phát triển năng lực thông tin cho người học khác nhau. Điều 
này cũng khiến cho cách thức tích hợp năng lực thông tin vào chương trình đào tạo cũng khác nhau ở mỗi cơ sở đào tạo. Tuy nhiên, về tổng thể, việc trang bị năng lực thông tin cần phải được triển khai đồng thời tại thư viện và các lớp học. Bruce và Candy [26] khuyến cáo rằng các trường đại học nên triển khai việc tích hợp năng lực thông tin ở ba cấp độ: cấp độ môn học, cấp độ chương trình đào tạo, và cấp độ cơ sở giáo dục. Theo đó, ở cấp độ môn học: việc tích hợp được phản ánh trong nội dung môn học, các phương pháp dạy và học được sử dụng trên lớp, các nguồn học liệu được cung cấp và chỉ dẫn, và phương thức đánh giá việc học tập của sinh viên. Ở cấp độ chương trình đào tạo, Bruce và Candy $[20,26]$ đã chỉ ra giới hạn của việc tích hợp ở cấp độ môn học nếu như không đảm bảo được mối quan hệ của hoạt động phát triển năng lực thông tin với các nội dung khác của môn học. Ở cấp độ này, phần mô tả chuẩn đầu ra của chương trình đào tạo cần có những nội dung liên quan đến phát triển khả năng tự học và năng lực học tập suốt đời của người học, liên quan đến phát triển các kỹ năng tìm kiếm, khai thác, sử dụng thông tin, liên quan đến vấn đề liêm chính học thuật. Cuối cùng, ở cấp độ cơ sở giáo dục, tính sẵn sàng của nguồn nhân lực, hệ thống hỗ trợ học tập, cơ sở hạ tầng, ngân sách hỗ trợ đổi mới là những yếu tố cần thiết. Để đảm bảo việc phát triển năng lực thông tin cho sinh viên toàn trường thì việc nâng cao nhận thức về vai trò của năng lực thông tin đối với người học nói riêng và việc đảm bảo chất lượng các chương trình đào tạo nói chung cần được triển khai một cách nhất quán và thấu đáo trong toàn đơn vị.

\subsection{Tạo lập cơ chế phối hợp và thúc đẩy vai trò của các bên liên quan}

Trong trường đại học, có 3 bộ phận trực tiếp liên quan và tác động tới hoạt động học tập của người học là: giảng viên, cố vấn học tập, nhân viên thư viện. Giảng viên tác động đến người học thông qua phương pháp giảng dạy và nội dung giảng dạy ở mỗi học phần. Cố vấn học tập đóng vai trò hỗ trợ người học về mặt phương pháp và các yếu tố liên quan đến việc thích nghi với môi trường học tập. Cán bộ thư viện có trách nhiệm tạo lập nguồn học liệu, hướng dẫn và chỉ dẫn để cho sinh viên khai thác nguồn thông tin và học liệu sẵn có tại thư viện. Giảng viên và cố vấn học tập đóng vai trò khuyến khích và hướng dẫn sinh viên đạt được mục tiêu học tập thông qua việc tham gia tích cực vào các hoạt động dạy và học trên lớp.

Mô hình lý tưởng của sự phối hợp giữa ba bộ phận này là: i) Giảng viên áp dụng các phương pháp giảng dạy tích cực, các hoạt động kiểm tra đánh giá đòi hỏi người học phải vận dụng các kiến thức và kỹ năng khai thác, sử dụng thông tin từ nhiều nguồn khác nhau; ii) Cố vấn học tập hỗ trợ người học chuẩn bị về mặt phương pháp, tâm thế học tập, chỉ dần những hỗ trợ cần thiết cho người học; và iii) Cán bộ thư viện tổ chức các khóa tập huấn về kỹ năng tìm kiếm, thẩm định, tổ chức thông tin, cung cấp cho người học nguồn thông tin phù hợp với nhu cầu học tập và đáp ứng các yêu cầu kiểm tra đánh giá mà giảng viên giao cho sinh viên.

Có thể thấy được điều này rõ hơn qua bảng "Mục tiêu và trách nhiệm phát triển năng lực thông tin" do Hine [27, tr. 104] và các tác giả khác tổng kết.

Bảng 1. Mục tiêu và trách nhiệm phát triển năng lực thông tin cho sinh viên [27, tr. 104]

\begin{tabular}{|l|l|}
\hline Mục tiêu & Trách nhiệm \\
\hline Gắn việc đọc và suy nghĩ tích cực với lý thuyết và thực tiễn & $\begin{array}{l}\text { Cố vấn học tập } \\
\text { Giáo viên phụ trách môn học }\end{array}$ \\
\hline $\begin{array}{l}\text { Thiết lập động cơ và nhu cầu phát triển năng lực thông tin cho } \\
\text { người học }\end{array}$ & Giáo viên phụ trách môn học \\
\hline $\begin{array}{l}\text { Phát triển và mô hình hóa các kỹ năng viết và kỹ năng phân tích } \\
\text { phù hợp nhằm hỗ trợ cho việc ghi chép và làm báo cáo }\end{array}$ & Cố vấn học tập \\
\hline $\begin{array}{l}\text { Khuyến khích sinh viên thể hiện sự phát triển năng lực thông tin } \\
\text { của riêng mình }\end{array}$ & $\begin{array}{l}\text { Cố vấn học tập } \\
\text { Giáo viên phụ trách môn học }\end{array}$ \\
\hline
\end{tabular}




\begin{tabular}{|l|l|}
\hline Xác định nhu cầu thông tin phục vụ học tập và nghiên cứu & $\begin{array}{l}\text { Cán bộ thư viện } \\
\text { Cố vân học tập }\end{array}$ \\
\hline Phân tích và lập danh mục từ khóa để tìm kiếm thông tin & Cán bộ thư viện \\
\hline Phân tích các nguồn tin, cả truyền thống và phi truyền thống & Cán bộ thư viện \\
\hline $\begin{array}{l}\text { Xây dựng những chiến lược tìm kiếm thông tin đơn giản. Sử } \\
\text { dụng các kỹ thuật tìm kiêm hiệu quả }\end{array}$ & Cán bộ thư viện \\
\hline $\begin{array}{l}\text { Áp dụng các chiến lược tìm kiếm vào các hệ thống tìm kiếm } \\
\text { truyênn thống và hiện đại }\end{array}$ & Cán bộ thư viện \\
\hline $\begin{array}{l}\text { Xác định phạm vi thông tin phù hợp với mỗi lý thuyết và nghiên } \\
\text { cứu cụ thể }\end{array}$ & $\begin{array}{l}\text { Giáo viên phụ trách môn học } \\
\text { Cán bộ thư viện }\end{array}$ \\
\hline Phân tích, tổng kết, tổ chức, trao đổi và thẩm định thông tin & $\begin{array}{l}\text { Giáo viên phụ trách môn học } \\
\text { Cố vấn học tập } \\
\text { Cán bộ thư viện }\end{array}$ \\
\hline Phát triển các kỹ năng tư duy và phản ánh tích cực & $\begin{array}{l}\text { Giáo viên phụ trách môn học } \\
\text { Cố vấn học tập }\end{array}$ \\
\hline $\begin{array}{l}\text { Phân tích và diễn giải chất lượng, tính phù hợp của các nguồn } \\
\text { tin theo chủ đề trong mối quan hệ với việc quan sát thực tiễn, } \\
\text { nghiên cứu lý thuyết, và thực hiện nghiên cứu }\end{array}$ & Giáo viên phụ trách môn học \\
\hline
\end{tabular}

Qua bảng trên ta có thể thấy rõ ràng rằng sự cộng tác giữa các bộ phận trên sẽ đảm bảo cho tính bền vững của việc phát triển năng lực thông tin cho người học. Mối quan hệ của các bên liên quan quyết định tính hiệu quả của các chương trình phát triển năng lực thông tin [21, 28, 29]. Việc xây dựng và triển khai các chương trình đào tạo gắn với mục tiêu phát triển năng lực học tập suốt đời cho người học sẽ chỉ được đảm bảo nhờ sự gắn kết của các bên liên quan như trên.

\subsection{Xây dưng kế hoạch triển khai năng lực thông tin linh hoạt}

Không có một kế hoạch phát triển năng lực thông tin nào phù hợp và khả thi đối với mọi cơ cở đào tạo đại học. Tuy nhiên, vẫn có một số chiến lược chung có thể sử dụng được trong việc triển khai kế hoạch này. Nhìn chung, có thể thấy rằng việc tích hợp phát triển năng lực thông tin cho người học vào chương trình đào tạo được xem như là nhân tố chính của việc phát triển năng lực thông tin trong sinh viên. Bên cạnh đó, các khóa học và hội thảo liên quan đến năng lực thông tin cần phải được tổ chức một cách rộng rãi và thường xuyên trong các trường đại học.
Cần lưu ý rằng, trước khi tiến hành bất kỳ một phân hệ hay nội dung nào của các chương trình phát triển năng lực thông tin, tất cả những người tham gia, đặc biệt là người làm công tác quản lý giáo dục, cần hiểu rõ và đầy đủ tầm quan trọng của năng lực thông tin, cũng như các yêu cầu về nhân lực, tài chính và phương thức triển khai các chương trình đó. Theo tác giả Bruce [19], việc triển khai các chương trình phát triển năng lực thông tin chắc chắn sẽ dẫn đến những thay đổi to lớn trong các quy trình dạy và học ở trường đại học. Tác giả này cho rằng các khóa học và môn học nên được thiết kế để đảm bảo rằng sinh viên có thể học tập một cách thường xuyên với các hệ thống và nguồn thông tin khác nhau. Tuy nhiên, cần lưu ý rằng năng lực thông tin không thể chỉ là kết quả của một môn học cụ thể nào đó, mà nó chỉ có được bền vững thông qua những trải nghiệm và tích lũy từ các môn học.

Theo nghĩa này, Hiệp hội Cán bộ thư viện đại học Australia [30] đã đề xuất bản Huớng dẫn thực hiện tối uu việc phát triển năng lực thông tin trong các truờng đại học Australia với ba cấp độ triển khai thông qua nhiều quy định cụ thể. Tài liệu này đã được lựa chọn và sử dụng rộng rãi bởi nó đề xuất một hệ thống giải pháp khá toàn diện và thống nhất cho việc phát 
triển năng lực thông tin cho người học trong các trường đại học ở Australia. Theo đó, khi xây dựng kế hoạch triển khai, cần đảm bảo ba cấp độ thực hiện khác nhau. Cấp độ thứ nhất đề xuất phương án thực hành tối ưu từ góc độ những người làm nhiệm vụ xây dựng và định hướng chiến lược cho trường đại học, tức là cấp lãnh đạo. Cấp độ thứ hai là cấp độ điều hành, tức là các bộ phận chức năng quản lý, điều hành chương trình đào tạo của trường đại học. Cấp độ thứ ba gắn với việc triển khai cụ thể, thông qua các nhóm nhân sự trực tiếp tham gia giảng dạy, nghiên cứu, làm việc với sinh viên. Tất nhiên, sự phân chia này không tuyệt đối: không có một cấp độ nào tồn tại độc lập với các cấp độ còn lại, cũng như việc triển khai có thể tiến hành đồng thời hoặc đan xen giữa các cấp độ. Trên thực tế, rất nhiều trường đại học ở Australia thường bắt đầu các chương trình phát triển năng lực thông tin cho sinh viên của mình ở cấp độ vĩ mô với sự điều chỉnh các tiêu chí tốt nghiệp đối với sinh viên toàn trường, điều chỉnh chuẩn đầu ra và nội dung dạy và học của các chương trình đào tạo.

\section{Kết luận}

Có thể thấy, các giá trị bản địa của văn hóa học thuật trong giáo dục đại học đóng vai trò vô cùng quan trọng trong việc xây dựng chiến lược phù hợp để phát triển năng lực thông tin cho sinh viên trong giáo dục đại học Việt Nam. Về mặt nhận thức, nhà trường cần phải đưa khái niệm năng lực thông tin vào các môi trường học tập cá nhân của sinh viên để họ nhận ra vai trò của năng lực thông tin trong việc tiếp thu và nâng cao khả năng thích ứng với bối cảnh học tập và làm chủ thế giới thông tin của chính mình. Bên cạnh đó, cần lưu ý các đặc điểm đặc thù về phong cách và môi trường học tập của sinh viên khi xây dựng các chỉ số đánh giá năng lực thông tin của sinh viên.

Bối cảnh hiện tại đòi hỏi các trường đại học ở Việt Nam cần tính đến một chiến lược đào tạo có chiều sâu và phù hợp với xu thế chung của thế giới. Điều cần làm trước mắt đối với các trường đại học là xác định rõ ràng mục tiêu đào tạo, xây dựng hệ thống các tiêu chí tốt nghiệp, chuẩn đầu ra gắn với việc trang bị cho người học khả năng học tập suốt đời, có khả năng thích ứng với các bối cảnh sống, học tập, làm việc khác nhau. Cốt lõi và động lực để thực hiện những mục tiêu và chuẩn đầu ra đó chính là năng lực thông tin của người học. Để triển khai phát triển năng lực thông tin hiệu quả cho người học, cán bộ thư viện, giảng viên, cố vấn học tập và những người làm quản lý cần phối hợp xây dựng những chiến lược triển khai phát triển năng lực thông tin cho sinh viên một cách cụ thể. Sự hợp tác và liên kết giữa các bên liên quan này là chìa khóa để đảm bảo sự thành công cho các chương trình phát triển năng lực thông tin tại trường đại học.

\section{Lời cảm ơn}

Nghiên cứu này được tài trợ bởi Đại học Quốc gia Hà Nội trong đề tài mã số QG. 15.47

\section{Tài liệu tham khảo}

[1] CRL Presidential Committee on Information Literacy, Final Report,

<http://www.ala.org/acrl/publications/whitepapers/pr esidential >/,1989 (accessed on: June $15^{\text {th }}, 2020$ ).

[2] N. X. Huy, Delivering Information Literacy Programmes in the Context of Network Society and Cross-Cultural Perspectives, World Library and Information Congress: 76th Ifla General Conference and Assembly,

https://www.ifla.org/past-wlic/2010/74-nghiemen.pdf/, 2010 (accessed on: February $15^{\text {th }}, 2020$ ).

[3] A. Firmanto, N. S. Degeng, Information Literacy in Class Culture-Based Learning, Advances in Social Science, Education and Humanities Research, Vol. 231, 2018, pp. 220-224.

[4] K. L. Spitzer, M. B. Eisenberg, C. A. Lowe (Eds), Information Literacy: Essential Skills for the Information Age, Syracuse, New York, ERIC Clearinghouse on Information \& Technology, Syracuse University, 1998.

[5] C. Bruce, Seven Faces of Information Literacy, Adelaide, Auslib Press, 1997.

[6] F. W. Horton et al., Overview of Information Literacy Resources Worldwide, 2nd Edition, UNESCO, 2014.

[7] J. Cheek et al., Finding Out: Information Literacy for the 21st Century, Melbourne, McMillan Education Australia, 1995. 
[8] A. Bundy, For A Clever Country: Information Literacy Diffusion in the 21 st century, $<$ https://trove.nla.gov.au/version/217759024>/, 2001 (accessed on: June 20 ${ }^{\text {th }}, 2020$ ).

[9] T. Duong, The Role of Information Literacy for Students in Higher Education, Conference Proceeding on IT Infrastructure for the Library System in the Process of Education Innovation in Vietnam, 2016.

[10] N. T. T. Giang, Solutions for improving students' information literacy at Hanoi University of Industrial Textile, Hanoi University of Industrial Textile, $<$ http://hict.edu.vn/trung-tam-thu-vien/giai-phapnang-cao-nang-luc-thong-tin-cho-sinh-vien-truongdai-hoc-cong-nghiep-det-may-ha-noi.htm>/, 2020 (accessed on: February 25 ${ }^{\text {th }}, 2021$ ).

[11] Anziil (Ed), Australian and New Zealand Information Literacy Framework: Principles, Standards and Practice, Adelaide, Australian and New Zealand Institute for Information Literacy, $<$ https://www.utas.edu.au/_data/assets/pdf_file/0003/7 9068/anz-info-lit-policy.pdf >/, 2004 (accessed on: October $4^{\text {th }}, 2020$ ).

[12] Acrl Information Literacy Competency Standards for Higher Education, Chicago, Association of College and Research Libraries, 2000.

[13] T. K. Van, Information Literacy Education - An Indispensable Trend in Public Libraries in Vietnam, Vietnam Library Journal, No. 3, 2017, pp. 3-7.

[14] G. Trentin, Networked Collaborative Learning: Social Interaction and Active Learning, Chandos, Oxford, 2010.

[15] H. B. Rader, Information Literacy-An Emerging Global Priority, White Paper Prepared for UNESCO, the U.S National Commission on Libraries and Information Science, and the National Forum on Information Literacy, for Use at the Information Literacy Meeting of Experts, Prague, The Czech Republic, 2002.

[16] I. Doskatsch, Collaboration Between Academics and Librarians; What are the Challenges? Adelaide, University of South Australia, 2001.

[17] I. Doskatsch, Perceptions and Perplexities of the Faculty-librarian Partnership: An Australian Perspective, Reference Services Review, Vol. 31, No. 2, 2003, pp. 111-121.

[18] A. Bundy, Beyond Information: The Academic Library as Educational Change Agent, 7th International Bielefeld Conference, Germany, 2004.

[19] C. Bruce, Information Literacy as a Catalyst for Educational Change: A Background Paper, White
Paper Prepared for UNESCO, the U.S National Commission on Libraries and Information Science, and the National Forum on Information Literacy, for Use at the Information Literacy Meeting of Experts, Prague, The Czech Republic, 2002.

[20] C. Bruce, P. Candy (Eds), Information Literacy Around the World: Advances in Programs and Research, Wagga Wagga, Centre for Information Studies, Charles Sturt University, 2000.

[21] T. Duong, Requirents for Students' Information Literacy, Ha Tinh University,

$<$ http://www.htu.edu.vn/tin-tuc-su-kien/cac-yeu-caudoi-voi-kien-thuc-thong-tin-cua-sinh-vien-hiennay.html>/, 2015 (accessed on: February 10 $0^{\text {th }}, 2021$ ).

[22] C. Bruce, Faculty-Librarian Partnerships in Australian Higher Education: Critical Dimensions, Reference Services Review, Vol. 29, No. 2, 2001, pp. 106-115.

[23] M. M. Warmkessel, J. M. McCade, Integrating Information Literacy into the Curriculum, Research Strategies, Vol. 5, No. 2, 1997, pp. 82-88.

[24] L. S. F. Farmer, Facilitating Faculty Incorporation of Information Literacy Skills Into Cirriculum Through the Use of Online Instruction, Reference Services Review, Vol. 31, No. 4, 2003, pp. 307-312.

[25] C. Brown, T. J. Murphy, M. Nanny, Turning Techno-Savvy into Info-Savvy: Authentically Integrating Information Literacy into the College Curriculum, The Journal of Academic Librarianship, Vol. 29, No. 6, 2003, pp. 386-398.

[26] C. Bruce, P. Candy, Developing Information Literate Graduates: Prompts for Good Practice, Brisbane, Queensland University of Technology, 1995.

[27] A. Hine, Embedding Information Literacy in A University Subject through Collaborative Partnerships, Psychology Learning and Teaching, Vol. 2, No. 2, 2002, pp. 102-107.

[28] A. Folk, Reframing Information Literacy as Academic Cultural Capital: A Critical and EquityBased Foundation for Practice, Assessment, and Scholarship, College \& Research Libraries, Vol. 80, No. 5, 2019, pp. 658-673, https://doi.org/10.5860/crl.80.5.658 >.

[29] I. F. Rockman, Integrating Information Literacy Into the Higher Education Curriculum: Practical Models for Transformation, San Francisco, Jossey-Bass, 2004.

[30] Council of Australian University Librarians (CAUL), Best Practice Characteristics for Developing Information Literacy in Australian Universities, <https://www.webcitation.org/5RlpmQMJr>/, 2000 (accessed on: February 25 ${ }^{\text {th }}, 2021$ ). 